\title{
Commentary: Trust behavior in Parkinson's disease: results of a trust game experiment
}

\author{
Gerhard Ransmayr \\ Dept. of Neurology 2, Kepler University Hospital, Krankenhausstr 9, A-4020 Linz, Austria
}

\section{Article Info}

\section{Article Notes}

Received: April 24, 2018

Accepted: May 30, 2018

${ }^{*}$ Correspondence:

Dr. Gerhard Ransmayr, MD

Dept. of Neurology

Kepler University Hospital

Krankenhausstr

A-4020 Linz, Austria;

Email: Gerhard.Ransmayr@kepleruniklinikum.at

C 2018 Ransmayr G. This article is distributed under the terms of the Creative Commons Attribution 4.0 International License

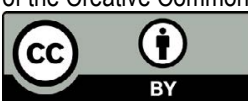

\section{Keywords:}

Parkinson's disease

Trust

Risk

Financial matters

Avatar
Parkinson's disease (PD) is characterized by a combination of levodopa responsive motor symptoms (akinesia, rigidity, postural instability including impairment of gait and posture, resting tremor) and vegetative, sensory, cognitive and neuropsychiatric changes ${ }^{1}$. Cognitive function attributed to the frontal lobes and their connections, such as planning of complex decisions and efficient strategies, may be involved in the early phase of PD and PD related dementia ${ }^{2,3}$. Trust in a person is the belief or conviction that this person fulfils certain positive expectations. Trust is essential for the functioning of relationships of persons. Studies have demonstrated that trust behavior involves neuronal circuits of the basal ganglia, the frontal lobes and the limbic system, which may be affected in $\mathrm{PD}^{4-6}$. Moreover, PD patients may exhibit anxiety, depression, or psychosis, which may compromise trustful reasoning and behavior ${ }^{7}$. The question arises whether or not trust behavior differs between PD patients and normal controls. To test trust behavior in PD in nondemented, non-apathetic PD patients Javor et al. ${ }^{4}$ chose a frequently used and easily understandable paradigm of trust, the Trust Game, ${ }^{8}$ in which emotionally neutral faces of young persons (age 20-30, gender equally distributed, 16 faces of avatars and 16 of real persons) were consecutively presented on a screen. The test person judged the financial trustworthiness of these individuals, as follows: The test person (trustor) sent a certain amount of money (maximum 10 Euros) to the trustee, which the investigator multiplied by 6 . The trustee then decided whether or not he/she would send money back to the trustor, and, if yes, which amount. Twenty (10male, 10 female) non-demented (Mini Mental State Examination score $>26$, mean \pm standard deviation (SD)28.4 \pm 1.6 ), otherwise healthy PD patients on levodopa therapy (15 patients also on a dopamine agonist) were included. The age of the PD patients was $72.3 \pm 9.16$ (mean \pm SD), disease duration $39 \pm 41$ months, UPDRS motor score 19.85 \pm 10.6 , Hoehn and Yahr score median 2. Patients presented no evidence of apathy, impulsive or compulsive behavior. PD patients were compared to twenty healthy control subjects matched for age, gender, income class, Mini Mental State Examination scores and confession.

In order to test whether or not risk taking interferes with trust behavior, the Trust Game was combined with a Game of Dice task ${ }^{9}$. A virtual dice and a shaker cup were presented on a screen. In each of 18 trials (dice rolls) test persons guessed which number would come up on the next roll. They could choose one of the various single numbers of the dice or a combination 2,3 or 4 different numbers. The higher the risk (i.e. the lower the number of choices) the higher was the gain of the trial. Choosing one or two numbers was considered as high-risk behavior.

The results of the Trust Game and the Game of Dice task differed 
between the PD patients and healthy control persons. In the Trust Game, the mean investment sum of PD patients was significantly lower than that of healthy control persons (mean $3.43 \pm 2.0$ versus $5.53 \pm 1.56$ Euros), whereas in the Game of Dice task, the number of high-risk choices (one or two number choices) was significantly higher in the PD group than in the controls (mean $10.2 \pm 3.93$ versus $7.05 \pm 3.62$ ). Disease duration, medication or severity of PD did not determine trust behavior. One cannot rule out that the facial recognition differed between the PD patients and the control persons. The PD patients were free of symptoms of major neurocognitive or neuropsychiatric symptoms including also apathy. Therefore, dementia or neuropsychiatric symptoms might not determine the findings. It is possible that the PD patients chose a more cautious strategy in the Trust Game (harm avoidance versus a chance of immediately available financial reward $^{10,11}$ ). The Trust Game was a novel situation (participation in a trust paradigm for the first time) and there was limited information about the trustee (only the facial expression). In summarizing, the study suggests that PD patients are reluctant to transfer money to a person who is only visually assessable. On the other hand, PD patients tend to make more risky decisions than control persons in a rather familiar paradigm (Game of Dice). This altered trust and risk taking behavior could play a relevant role in everyday life, in particular concerning money transfer and investment, but also in the relationship to medical personal and therapies. One may criticize that the data was obtained in small collectives. However, the patients and the control subjects were carefully selected and comorbidities ruled out. Moreover, the differences between the groups were significant although the groups were small. It is likely that reduced trust of PD patients is due to specific neuropsychological factors, which are unrelated to dementia or neuropsychiatric symptoms and might be due to differential assessment of trustworthiness of natural faces, maybe different emotional recognition of faces in PD compared to controls ${ }^{12}$.

\section{References}

1. Hughes AJ, Daniel SE, Kilford L, et al. Accuracy of clinical diagnosis of idiopathic Parkinson's disease: a clinico-pathological study of 100 cases. J Neurol Neurosurg Psychiatry. 1992 Mar; 55(3): 181-4.

2. Lees AJ, Smith E. Cognitive deficits in the early stages of Parkinson's disease. Brain. 1983 Jun; 106 (Pt 2) :257-70.

3. Taylor AE, Saint-Cyr JA, Lang AE. Frontal lobe dysfunction in Parkinson's disease. The cortical focus of neostriatal outflow. Brain. 1986 Oct; 109 ( Pt 5): 845-83.

4. Javor A, Riedl R, Kirchmayr M, et al. Trust behavior in Parkinson's disease: results of a trust game experiment. BMC Neurol. 2015 Jul 31; 15: 126. doi: 10.1186/s12883-015-0374-5.

5. Kalaitzakis ME, Christian LM, Moran LB, et al. Dementia and visual hallucinations associated with limbic pathology in Parkinson's disease. Parkinsonism Relat Disord. 2009 Mar; 15(3): 196-204. doi: 10.1016/j.parkreldis.2008.05.007.

6. Uribe C, Segura B, Baggio HC, et al. Patterns of cortical thinning in nondemented Parkinson's disease patients. Mov Disord. 2016 May; 31(5): 699-708. doi: 10.1002/mds.26590.

7. Weintraub D, Burn Dj. Parkinson's Disease: The quintessential neuropsychiatric disorder. Mov Disord. 2011 May; 26(6): 1022-1031.

8. Berg J, Dickhaut J, McCabe K. Trust, reciprocity, and social history. Games Econ Behav. 1995; 10: 122-142 doi: 10.1006/game.1995.1027

9. Euteneuer F, Schaefer F, Stuermer R, et al. Dissociation of decisionmaking under ambiguity and decision-making under risk in patients with Parkinson's disease: A neuropsychological and psychophysiological study. Neuropsychologia. 2009; 47(13): 2882-90.

10. Santangelo G, Garramone F, Baiano C, et al. Personality and Parkinson's disease. A meta-analysis. Parkinsonism Relat Disord. 2018 April; 49: 67-74.

11. Voon V, Sohr M, Lang AE, et al. Impuls control disorders in Parkinson disease: a multicenter case-control study. Ann Neurol. 2011; 69: 986-96.

12. Saenz A, Doé de Maindreville A, Henry A, et al. Recognition of facial and musical emotions in Parkinson's disease. Eur J Neurol. 2013 Mar; 20(3): 571-7. doi: 10.1111/ene.12040. Epub 2012 Dec 24 